\title{
LA DIRECCIÓN ORQUESTAL Y SU DIMENSIÓN SOCIAL: HACIA LA INCLUSIÓN DE LA MUJER
}

\author{
THE ORCHESTRAL CONDUCTING AND ITS SOCIAL \\ DIMENSION: TOWARDS THE INCLUSION OF WOMEN
}

\section{Sandra SOlER CAMPo y Elia SANELEUTERIO}

Authors / Autoras:

Sandra Soler Campo

Universitat de Barcelona

Barcelona, Spain

sandra.soler@ub.edu

https://orcid.org/0000-0002-5560-1415

Elia Saneleuterio

Grupo de Investigación TALIS - Universitat de València

Valencia, Spain

elia.saneleuterio@uv.es

https://orcid.org/0000-0003-4060-9518

Submitted / Recibido: 24/10/2020

Accepted / Aceptado: 09/12/2020

To cite this article / Para citar este artículo: Soler Campo, S. y Saneleuterio, E. (2022).

La dirección orquestal y su dimensión social: hacia la inclusión de la mujer. Feminismo/s, 39, 287-307. https://doi.org/10.14198/

fem.2022.39.11

Licence / Licencia:

This work is licensed under a Creative Commons Attribution 4.0 International.

\section{(c) (1)}

(C) Sandra Soler Campo y Elia Saneleuterio

\section{Resumen}

Por influencia de las teorías freudianas suele decirse que, en el contexto de una orquesta, la batuta representa la virilidad, al ser un elemento usado única y exclusivamente por quien ostenta el liderazgo de aquella. El director, batuta en mano, se transforma en un mediador entre el conjunto musical, la obra y el público. Sin embargo, esta analogía únicamente funciona a nivel de recepción musical y social cuando estamos ante un líder varón. El presente artículo analiza con perspectiva de género el rol del director de orquesta partiendo de su origen, como figura que surge en el siglo XIX y evoluciona hasta la actualidad. En concreto se exponen los resultados de una investigación cuyo objetivo es, dada la escasez de mujeres que se dedican a la dirección orquestal, explorar la percepción sobre los papeles de este tipo de liderazgo femenino e identificar los obstáculos que sus protagonistas han tenido que vencer durante su formación musical y, posteriormente, una vez han accedido al mundo laboral. Para ello, se han tenido en cuenta 36 entrevistas realizadas durante los años 2014 y 2020 y el informe ¿Dónde están las mujeres en la música sinfónica?, elaborado por la asociación Clásicas y Modernas. Su análisis conduce a identificar 
una serie de patrones que obstaculizan la presencia femenina en el ámbito de la dirección orquestal, entre los que destacan la falta de referentes femeninos, la escasa normalización de la profesión de directora de orquesta, las dificultades de conciliación laboral y familiar y los problemas sociales en la recepción y actitud de los y las intérpretes que son dirigidos por una mujer.

Palabras clave: dirección orquestal; estereotipos de género; mujeres; liderazgo; música.

\begin{abstract}
Due to the influence of Freudian theories, it is often said that, in the context of an orchestra, the baton represents virility, as it is an element used exclusively by whoever holds the leadership of the orchestra. The conductor, baton in hand, becomes a mediator between the musical ensemble, the work, and the audience. However, this analogy only works at the level of musical and social reception when we are dealing with a male leader. This paper analyses the role of the conductor from a gender perspective, starting from its origin as a figure that emerged in the 19th century and evolved until today. Specifically, it presents the results of a research whose aim, given the scarcity of women who are dedicated to orchestral conducting, is to explore the perception of the roles of this type of female leadership and to identify the obstacles their protagonists have had to overcome during their musical training and, subsequently, once they have entered the working environment. To this end, 36 interviews conducted during the years 2014 and 2020 and the report Where are the women in symphonic music? elaborated by Clásicas y Modernas association, have been taken into account. The analysis leads to the identification of a series of patterns that hinder the presence of women in the field of orchestral conducting, some of them stand out: the lack of female referents, the scarce normalization of the profession of orchestra conductor, the difficulties of work and family reconciliation, and the social problems in the reception and attitude of the performers who are conducted by a woman.
\end{abstract}

Keywords: orchestral conduction; gender stereotypes; women; leadership; music.

\title{
1. INTRODUCCIÓN Y OBJETIVOS
}

En una orquesta, el principal objetivo del director o directora consiste en dirigir al conjunto de músicos que trabajan en la interpretación de una obra musical. Durante la duración del concierto, esta figura aparece como un ser dotado del poder a quien los músicos deben obediencia en cada una de sus indicaciones y gestos corporales.

Feminismo/s 39, January 2022, 287-307 
Mientras el concierto tiene lugar, dirección e intérpretes, acompañados de sus instrumentos y partituras, tienen un único fin: dar vida a la obra escrita por un compositor o compositora. Ese preciso instante requiere de la participación de todos y cada uno de ellos en un espacio-tiempo común para trabajar juntos.

En la dirección orquestal, y por influencia de las teorías freudianas, suele decirse que la batuta representa la virilidad, pues es un elemento usado única y exclusivamente por quien ostenta el liderazgo de aquella. El director, batuta en mano, se transforma en un mediador entre el conjunto musical, la obra y el público. Ante un público, este papel interpretativo añade a las consideraciones anteriores el rol de comunicarse con los espectadores y espectadoras mediante la vía gestual (Calderón et al., 2015).

Pero ¿ocurre lo mismo si se trata de una directora? Que este cargo orquestal lo ejerza un hombre o una mujer es un hecho que no deja indiferente a un público que está poco acostumbrado a la presencia femenina en esta posición de líder (Valls, s/f). Como sabemos, todas las posiciones de liderazgo, en los diferentes periodos de la historia de la música occidental, han sido monopolizadas por el sexo masculino. No obstante, se deben tener presentes los lentos y progresivos avances que las mujeres han hecho en el ámbito musical (Soler, 2019). Así, ya desde el siglo XIX se las animó a continuar con su formación musical, si bien cabe no olvidar que no fueron pocas cuyos maridos o padres les prohibieron aparecer en el escenario ante un auditorio o publicar sus obras musicales con su propio nombre (Pendle, 1991).

Si nos centramos en el papel de las directoras de orquesta, su autoridad es considerada, a menudo, como artificial e incluso una distracción sexual (Rhodes, 2014). Una de las explicaciones podemos hallarla en la teoría de Ridgeway (2008), según la cual las percepciones individuales están influenciadas por las creencias culturales, en las que el género es un factor significativo que moldea el comportamiento y las relaciones sociales en un contexto institucional. Centrándonos en el caso que nos ocupa, el modo en que uno u otro sexo dirige a la agrupación musical ha sido un tópico que ha suscitado el interés de sociólogos y musicólogos. Así, hay autores (De Laleu, 2016; Park et al., 2016) que afirman que los hombres y las mujeres usan lenguajes distintos, cuya mayor diferencia reside en el grado de calidez interpersonal: uno es más amigable y cercano, mientras que el otro se considera socialmente 
más distante, incluso desagradable; ellas se centran en los sujetos, ellos en los objetos. Además, y contrariamente a lo esperado, las mujeres utilizan un poco más el estilo asertivo que los varones (Park et al., 2016).

Las directoras cuyas entrevistas se analizan en Soler (2019) confirman que todas sienten la necesidad de utilizar estrategias variadas para conseguir autoridad cuando se sitúan frente al grupo orquestal. Las bromas o connotaciones sexuales, utilizadas para hacer que una directora de orquesta se sienta incómoda con el fin de probar sus reacciones o, más precisamente, para desafiar su autoridad, son una constante en la relación entre la directora de orquesta y el conjunto instrumental (De Laleu, 2016; McClary, 1991).

En definitiva, la presente investigación cuestiona la figura del director de orquesta. Tanto el rol del director como su estatus y representación simbólica, continuando investigaciones como las de Ravet $(2000,2015)$ y Soler (2019), cuyos objetivos exploraban, respectivamente, las cooperaciones y negociaciones en las relaciones orquestales y las dificultades, avances y metas de las músicas, incluidas las directoras. Así pues, la pretensión de la presente investigación es explorar la percepción sobre la dirección de orquesta desde un punto de vista femenino e identificar los obstáculos que han tenido que vencer las mujeres que se dedican a ello, tanto en el mundo laboral como, previamente, durante su formación musical.

\section{LA FIGURA DEL DIRECTOR O DIRECTORA DE ORQUESTA}

La figura del director tal y como la conocemos en la actualidad se desarrolló durante las primeras décadas del XIX. Paralelamente, este fue el siglo en que se fue ampliando y estableciendo la sinfonía romántica. A partir de entonces, y en consonancia con la estética y pensamiento del Romanticismo, el director fue considerado por el público y por la sociedad en general como una especie de ídolo o superintérprete.

El ritual del concierto sinfónico es un claro ejemplo de la escenificación de poder. En un primer momento, son los músicos los que ordenadamente toman asiento, pero el público no comienza a aplaudir hasta que, unos momentos después, el director hace su aparición en el escenario. Su ascenso hacia el atril y su gesto indican el silencio sepulcral que será necesario antes de comenzar y dar paso a la interpretación musical. En este punto 
cabe preguntarse si se mantiene intacto el respeto a la autoridad en el caso de ser una mujer quien dirige la orquesta.

El acceso femenino a la enseñanza musical en los conservatorios y universidades a partir de la segunda mitad del siglo XIX influyó positivamente en las jóvenes que querían recibir una formación musical. En el ámbito de la dirección orquestal, incluso en el siglo xx, no estuvo bien visto que una mujer realizara estos estudios y mucho menos que se dedicara a ello (Alger, 2018). No obstante, sí existen mujeres que han asumido con éxito la función de directoras a lo largo de la historia. En el siglo XIX, debe destacarse a la directora, compositora e intérprete Fanny Mendelssohn, quien inició y dirigió sus propios conciertos dominicales, lo que era muy poco común en ese momento. Otra mujer destacada, en este caso a principios del siglo Xx, fue la inglesa Ethel Smyth, quien además de la composición de obras menores, compuso óperas y obras que han marcado un hito, como March of the Women. Por otra parte, a lo largo de la historia de la música ha habido orquestas femeninas, es decir, compuestas enteramente por mujeres. En la mayoría de los casos, estas músicas han seguido las indicaciones de una directora, de igual modo que en otros ámbitos tradicionalmente masculinos se evita que el liderazgo femenino se ejerza sobre varones (así las árbitras de fútbol, por ejemplo, no arbitran partidos de primera división masculina ${ }^{1}$ ). Un ejemplo de ello fue la Orchestre Féminin de París, fundada en 1930 por Jane Evrard, quien se convirtió así en la primera mujer que se dedicó profesionalmente a la dirección orquestal en Francia. Esta agrupación instrumental estuvo formada por instrumentistas que poseían buenos conocimientos musicales e interpretativos. Algunos compositores tales como Arthur Honegger escribieron para este conjunto.

Por otro lado, durante las primeras décadas del siglo xx, la radio fue un medio de comunicación que revolucionó el modo en que la sociedad de consumo podía acceder a las noticias y evidentemente también a las novedades musicales. En marzo de 1942, la orquesta canadiense de Montreal (MWSO)

1. Sobre las incoherencias y desigualdades que aún hoy sufren las mujeres que osan pisar el monopolio de los hombres en cualquier disciplina ironiza la obra Niñas que no tenemos ni puta idea, de Isabel Martí, estrenada en 2018 por la compañía teatral Els Indecents (https://vimeo.com/264427375). 
realizó una interpretación musical para la radio $\mathrm{CBC}$. Aunque sea evidente que la transmisión de dicho evento musical y un concierto en directo no son lo mismo, la emisión fue una de las pocas oportunidades profesionales que tuvieron las mujeres intérpretes, pues no eran visibles para el público (Noriega, 2010).

Aunque el acceso femenino a los estudios musicales reglados tuvo lugar durante la primera parte del XIX, las mujeres estuvieron escasamente representadas en el mundo musical profesional durante muchas décadas. Y, en concreto en la dirección orquestal, incluso en la actualidad la presencia femenina representa un porcentaje irrisorio, como se comentará más adelante. Algunos autores (Oppegard et al., 2005) afirman que ello se debe a que los hombres prefieren trabajos realistas, investigadores y emprendedores, mientras que las mujeres tienden a ocupaciones sociales, artísticas y convencionales. Ello es, no obstante, contradictorio, si tenemos en cuenta que el sexo femenino representa un porcentaje superior al 50\% en los estudios artísticos y creativos, pero aun así el dominio masculino sigue siendo significativo tanto en las industrias culturales como en los puestos de dirección (Scharff, 2018).

En la actualidad la mujer directora de orquesta continúa siendo una rara avis. A modo de ejemplo, en Estados Unidos, país en el que surgió la musicología feminista y, consecuentemente, la reivindicación de la figura de la mujer música, tan solo el 5\% de mujeres dirige conjuntos orquestales. Además, y en paralelo a lo que ocurre en otras áreas, los salarios y categorías son inferiores a aquellos a los que acceden los hombres (Gould, 2003). En 1965, Herbert von Karajan escribió una carta de recomendación para Sylvia Caduff, con el siguiente mensaje: «Espero que su única desventaja, a saber, ser mujer, no sea un obstáculo para el desarrollo de su carrera, lo cual espero sinceramente para ella» (cit. en LePage, 1980, p. 59). Medio siglo después, las directoras de orquesta todavía tienen que enfrentarse a muchos obstáculos para tener éxito y ver reconocido su trabajo.

Una de las causas que generan este problema son los estereotipos de género que persisten, es decir, las figuraciones que asocian lo masculino con la acción, el poder, la competitividad o la insensibilidad y lo femenino con la pasividad, la cooperación, la expresividad o la sensibilidad, ideas que, a nivel social, van evolucionando muy lentamente en el imaginario colectivo 
(Castillo-Mayén y Montes-Berges, 2014). Al respecto, resultan muy esclarecedoras las entradas 'agresividad' (pp. 23-26) y 'poder' (pp. 240-247) del Diccionario ideológico feminista de Victoria Sau (2000). Existen cuatro dimensiones en la identidad de género, y todas ellas son blanco de estereotipos: cuerpo, capacidades intelectuales, carácter e interacciones sociales (Ortega, 1998). En lo que respecta a los prejuicios contra las directoras de orquesta, los estereotipos más influyentes tienen que ver con las capacidades, sobre todo, en las relaciones sociales y de liderazgo, pero el resto también ejercen su influencia (Lazarou, 2017).

Otro de los factores que favorecen el éxito y la visibilidad de las directoras de orquesta es cómo se las representa en la prensa. Actualmente, el sello femenino en la dirección suele ser noticia, y se celebra como triunfo o ligero avance hacia la igualdad (AFP, 2020a; ENS, 2020). También van en aumento los actos académicos dedicados a visibilizar su trabajo, como premios, congresos y simposios específicamente sobre directoras de orquesta (AFP, 2020b; Franco, 2020; Leonardo, 2020; Piña, 2020).

Asimismo, en nuestro país debe destacarse la formación instrumental Almaclara, dirigida por la gaditana Beatriz González Calderón, donde desde hace más de una década se interpretan obras de mujeres que escasas veces forman parte del repertorio de los programas de concierto habituales. El nombre de la formación, Almaclara, surge de la unión onomástica de dos de las más célebres compositoras e intérpretes del siglo XIX, Alma María Schindler (1879-1964) y Clara Josephine Wieck (1819-1896).

A pesar de todo lo apuntado, debe destacarse que no todo es tan positivo, según se desprende del informe ¿Dónde están las mujeres en la música sinfónica?, realizado por la asociación Clásicas y Modernas (Gutiérrez et al., 2019), en colaboración con la Fundación SGAE, Mujeres en la Música y Mujeres Creadoras de Música en España, en el que se analiza la presencia femenina tomando como referencia los conciertos realizados por las orquestas españolas de referencia durante la temporada 2016-2017. En lo que respecta a este trabajo de investigación, exponemos los resultados relacionados con el número de directoras que han dirigido las principales orquestas nacionales (gráfico 1). Los datos ponen de manifiesto que la participación femenina en el ámbito de la dirección orquestal está aún muy lejos de lo que sería deseable para alcanzar la paridad, puesto que solamente en 4 de las 11 orquestas 
seleccionadas ha llevado la batuta alguna mujer durante la temporada analizada; pero lo más alarmante es que solo ha habido un nombre femenino en cada una, frente a los casos restantes contemplados, correspondientes a 100 hombres directores en las mismas orquestas durante el mismo período (Gutiérrez et al., 2019).

Gráfico 1. Orquestas españolas dirigidas por mujeres la temporada 2016/17. Fuente: Elaboración propia a partir de los datos de Gutiérrez et al. (2019)

\section{Orquestas Música Clásica}

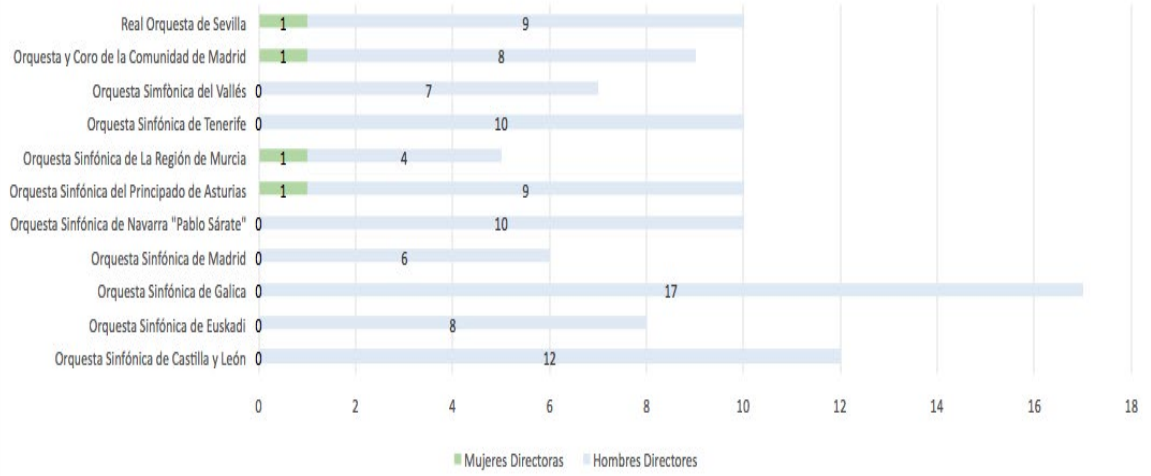

Por otra parte, según el mismo estudio, solamente el 5\% de las personas que se dedican profesionalmente a la dirección de orquesta son mujeres, lo que en datos absolutos supone 8 de 167; ocho directoras que han dirigido menos conciertos de media que sus pares varones. Concretamente han sido 24 las obras dirigidas por mujeres, de un total de 668 analizadas, lo que representa el $4 \%$ de los conciertos programados.

\section{LAS RELACIONES ENTRE EL DIRECTOR DE ORQUESTA Y LOS MÚSICOS}

Entre los estilos de liderazgo, los hay con impacto negativo en el ambiente de trabajo, como los que tienden a la represión o al excesivo control, mientras que el resto sí tendrían un impacto positivo en el clima. Hay múltiples 
fuentes que los explican y categorizan (Boisnard y Melander, 2018), pero por su amplia aceptación entre los especialistas tomamos la clasificación de Daniel Goleman, quien plantea el liderazgo a través de seis estilos diferentes, que pueden extrapolarse al ámbito musical y, en concreto, a la dirección orquestal.

En primer lugar, y considerado como el menos efectivo de los estilos de liderazgo en la mayoría de las situaciones, el estilo restrictivo/represivo crea una situación de malestar y miedo (Goleman, 2000). Este estilo de liderazgo es característico de aquellos directores que no propician que los músicos aporten nuevas ideas ni sugerencias y cuya iniciativa y modus operandi es planteada de modo incuestionable.

En segundo lugar, encontramos el líder controlador/obsesivo. Los directores que utilizan este estilo establecen estándares y objetivos extremadamente exigentes para sus músicos. A pesar de que animan al conjunto de intérpretes a mejorar en ciertos pasajes, a nivel técnico e interpretativo tienden a exigir objetivos difícilmente alcanzables, hasta el punto de que aquellos que no logren seguir su ritmo pueden llegar a ser excluidos de la plantilla orquestal.

El tercer estilo que establece Goleman, el autoritario, es el más efectivo de entre los diferentes modelos que propone. Uno de los objetivos de este estilo es mantener motivados a los músicos. El líder establece de un modo claro una serie de metas u objetivos que deben alcanzarse. De este modo, pueden saber por qué están trabajando de ese modo y no de otro, además de disponer de la libertad de poder experimentar, innovar y proponer nuevas ideas.

En cuarto lugar, el líder afiliativo tiene como objetivo traer eficiencia a la compañía, con el principal objetivo de construir la lealtad de los empleados al involucrarse en su trabajo. Para ello, la estrategia es generar felicidad y armonía, sentimientos con los que no solo es más fácil ser leales al líder, sino también apreciar más a los colegas. De esta manera los músicos compartirán más ideas e inspiración juntos para ser más creativos y productivos. Se suele señalar que estas dinámicas van unidas a la flexibilidad, pues se favorece la libertad de que cada uno trabaje de la manera que considere más eficaz. Además, un líder afiliativo proporciona retroalimentación a sus seguidores, lo que lleva a una amplia reacción positiva y tiene una especial potencia hacia los subordinados. A pesar de todas estas ventajas, el estilo de afiliación 
presenta serios inconvenientes que lo hacen poco recomendable para lograr competitividad, empezando por el hecho de que un rendimiento pobre o mediocre podría ser asimilado como aceptable y tolerado, pues podría permanecer sin corregir. Asimismo, confiando demasiado en este estilo, la gente podría no percibir los consejos constructivos que necesita para seguir a través de complejos desafíos y todo el grupo fracasaría.

El quinto tipo de liderazgo, el democrático, se refiere al del director que interactúa con el conjunto orquestal antes de tomar decisiones importantes. Es un líder que tiene en cuenta la diversidad de opiniones y atiende las sugerencias que se le plantean ante cualquier tipo de situación. Para que realmente funcione, los músicos deben ser competentes o estar lo suficientemente informados del tema que se va a debatir, para así poder dar un punto de vista con fundamentos y relevante.

Finalmente, el estilo de liderazgo propio del coach requiere una inversión de tiempo significativa para que realmente llegue a ser efectivo. Este tipo de líder dirigirá a los músicos con el objetivo de vencer los obstáculos que puedan encontrarse en su día a día identificando las fortalezas y debilidades de cada uno de ellos y así centrarse en alcanzar sus aspiraciones. En un principio, es posible que no se logren todos los objetivos fijados, pero sí se conseguirán posiblemente a largo plazo con constancia y trabajo.

Respecto al trabajo de la persona que realiza la dirección de la orquesta, este consta fundamentalmente de dos momentos: los ensayos y el concierto en directo. Previamente a ello, trabaja a fondo los diferentes contenidos musicales y extramusicales que contiene la partitura. Así pues, debe conocer qué es lo que ha de interpretar cada uno de los músicos y por tanto cuáles son las intenciones musicales del compositor de la pieza. Esquemáticamente, los diferentes encuentros entre el director y los músicos son los siguientes: el primer contacto con los músicos durante el primer ensayo; durante los posteriores ensayos, y después de la realización de un pasaje musical, es el momento para comentarios, indicaciones y peticiones que hace el director a sus músicos; al final de los ensayos, suelen tener lugar las expresiones puntuales de agradecimiento; finalmente, durante el concierto en directo, el director de orquesta saluda a los músicos, al público y/o al compositor, tanto antes como después de la actuación musical. 
Durante el transcurso del concierto, los músicos no pueden permitirse ninguna equivocación, a diferencia de cuando están ensayando, que pueden permitirse la repetición de la obra una y otra vez. Tampoco el director puede detener la interpretación ni dar un feedback a los músicos o hacerles repetir un fragmento que no ha sonado del todo bien. Así pues, se trata del preciso instante en el que se desarrolla toda la interpretación musical. Es la puesta en escena a nivel sonoro de toda una pieza musical (o varias) de principio a fin sin interrupción alguna, a menos que el compositor lo indique.

En un concierto en directo, ante un público, tienen lugar diferentes tipos de interacciones entre el director de orquesta y los músicos. En primer lugar, la llegada del director al escenario determina realmente el comienzo del concierto. Tanto sus gestos como sus movimientos informan de elementos interpretativos como los matices, las acentuaciones melódicas o rítmicas, el equilibrio entre los instrumentos o de las voces, pero también las inflexiones sonoras y la expresividad de la interpretación. Así, las indicaciones de tempo y el compás suelen realizarse con la mano; a través de los gestos manuales, el director indica a los músicos los momentos en los que deben entrar o salir, etc. Esta gramática construye los gestos y caracteriza la manera en que el líder dirige a los músicos. Todos estos intercambios se basan en una escucha activa por parte del director de orquesta.

En los ensayos se pueden observar las mismas direcciones de interacción y las mismas formas de intercambio que en los conciertos. La gran diferencia es que el ensayo genera reflexividad, mientras que en el concierto tanto el director como los músicos están concentrados en lograr, en un espacio y tiempo efímeros, la mejor interpretación posible. Además, a diferencia del concierto en directo, las indicaciones gestuales van a menudo acompañadas de instrucciones verbales e intercambios con los músicos, además de imágenes, con un vocabulario visual o metáforas con fines expresivos. A veces, incluso, anticipan ciertas dificultades en la realización de uno o varios pasajes musicales y ofrecen consejos para su mejora a nivel interpretativo (cómo tocar un pasaje concreto, cómo pronunciar una frase...).

Si el director de orquesta está satisfecho con el pasaje en particular o con la actuación en general, suele trasladarlo a los músicos de alguna manera. El modo de comunicarlo dependerá del estilo de liderazgo que ejerza hacia el conjunto orquestal. Así, en función del tipo de líder que sea, del diálogo 
y feedback que proporcione, pueden establecerse situaciones favorables (de cooperación) o desfavorables (de conflicto). Así, una situación de equilibrio con lo que los músicos puedan aportar -es decir, que sus opiniones sean escuchadas y que el líder no sea una autoridad única y absoluta- posibilitará un equilibrio que facilite la cooperación y evite el distanciamiento de los músicos e incluso situaciones de conflicto.

\section{METODOLOGÍA}

La entrevista ha sido el instrumento principal de recogida de datos que se ha utilizado para esta investigación. Ha permitido un acercamiento a varios sujetos que se dedican a la composición, interpretación, docencia y/o dirección orquestal. Este contacto directo ha aportado al estudio información muy relevante narrada en primera persona, relacionada con sus experiencias, opiniones, vivencias, situaciones pasadas y presentes en el contexto musical y a nivel personal.

La técnica de la entrevista ha permitido, además, obtener respuestas objetivas, más allá de juicios de opinión propios a partir de los análisis y de la bibliografía consultada durante la fase previa de investigación.

Para este estudio se han analizado los datos obtenidos a través de dos fuentes principales de información:

- 26 entrevistas realizadas entre 2014 y 2017 publicadas por Soler (2019), 9 de las cuales son exploratorias y 17 semiestructuradas.

- 10 entrevistas adicionales, realizadas ad hoc para este estudio a mujeres compositoras y directoras de orquesta durante los años 2019 y 2020 .

Los primeros 26 sujetos entrevistados fueron 3 hombres y 23 mujeres que se dedican a la composición o a la dirección orquestal y que a la vez lo combinan con la docencia en conservatorios y escuelas de música.

Las 10 entrevistas posteriores, que se desarrollaron durante el 2019 y 2020, se realizaron exclusivamente a directoras de orquesta españolas que están en activo en la actualidad.

Como se aprecia, se ha preferido entrevistar mayoritariamente a mujeres, puesto que se trata de la percepción y el análisis del mundo de la música 
culta respecto a la dirección de orquesta desde un punto de vista fundamentalmente femenino.

Los sujetos entrevistados en ambas fases pertenecen a diferentes generaciones, como puede observarse en el gráfico 2 .

Gráfico 2. Edad de los sujetos entrevistados en cada tanda, en porcentaje

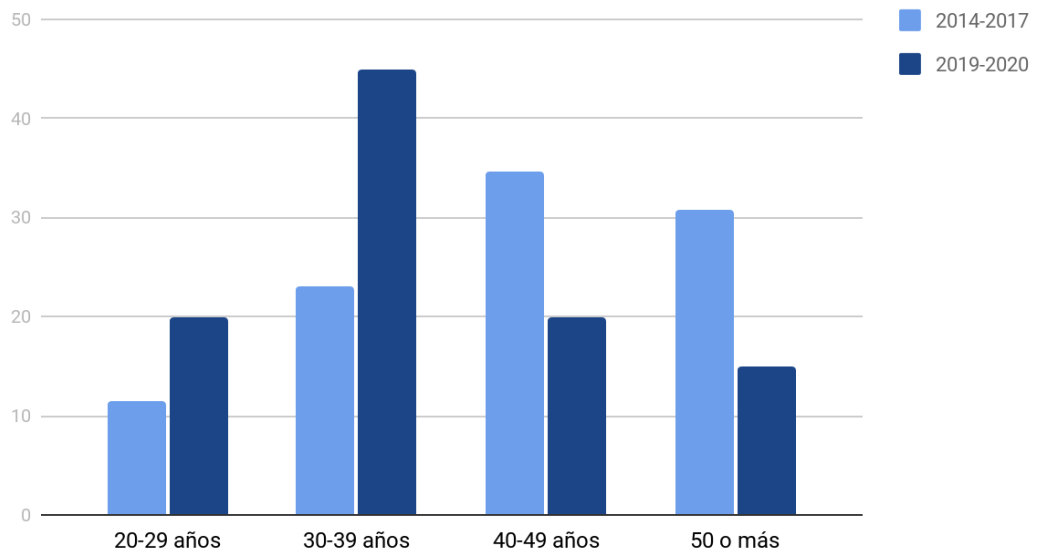

Las preguntas planteadas en las entrevistas mencionadas pueden clasificarse en los siguientes apartados: obstáculos, motivación, trato recibido, peso del género (maternidad, conciliación), avances y retos pendientes.

Las respuestas se transcribieron con un procesador de textos y las identidades fueron anonimizadas mediante un sistema de numeración.

\section{ANÁLISIS DE LOS RESULTADOS}

El análisis de las 36 respuestas a las entrevistas nos conduce a identificar diferentes obstáculos con los que se encuentran las directoras de orquesta. Para la exposición de los resultados, y teniendo en cuenta las limitaciones de extensión, transcribimos uno o dos fragmentos significativos que den muestra de cada uno de los núcleos de interés que han sido detectados en las entrevistas. 
En el alumnado, creo que hay bastantes más mujeres que hombres en casi todas las especialidades e incluso en el profesorado hay bastante equidad. Pero aún se mantiene el sistema piramidal que impide a las mujeres acceder sin renuncias a las cúpulas profesionales. (Entrevistada 4-2017)

Mi formación académica es como violonchelista. Ahí nunca he tenido problemas. El estudio de dirección ha sido siempre a través de maestros a los que admiraba y que me han enseñado a través de la música, independientemente a mi género. Creo que el problema no está ahí, sino una vez que sales al mundo laboral. Si que fue difícil presentar una orquesta integrada únicamente por mujeres y sí que faltan directoras de orquesta, sobre todo en formaciones con gran tradición o antigüedad. Creo que los proyectos nuevos cada vez ponen el foco más en la música y en el proceso creativo que en quién lo conforma. Como siempre debería haber sido. (Entrevistada 6-2019).

Respecto a la motivación, como se ve en los fragmentos anteriores, se percibe que, aunque no se han tenido dificultades a la hora de acceder a la formación elegida, sí se restringe posteriormente la entrada de mujeres al mundo profesional de la música. Además, durante los estudios, son pocos los referentes femeninos con que el estudiantado se familiariza (López-Navajas, 2015), lo que puede provocar que las alumnas tengan menos motivación que los alumnos, que sí ven ejemplos claros que seguir y con los que se pueden identificar más fácilmente. Y no es porque no existan, sino que simplemente estos referentes quedan excluidos de libros de texto y programas formativos. Así se expresa en la entrevista 2-2020:

Siempre tengo mujeres que me inspiran, pero no solo en la música. En el resto de las Artes, en Ciencias y en Humanidades. Hay muchos ejemplos de vida, de pensamiento que son grandes referentes para mí. Si hablo de música, mis cinco esenciales son Anna Magdalena Bach, Nannerl Mozart, Fanny Mendelssohn, Clara Schumann y Alma Mahler. Pero si pienso en mujeres a las que admiro, de las que aprendo constantemente y a las que me gustaría parecerme, sin duda aparecen Camille Claudel, Virginia Woolf, Simone de Beauvoir, Marie Curie, Santa Teresa de Jesús, La Roldana, Elena Fortún, Rita Levy, etc. No obstante, de ellas poco escuché hablar (de algunas nunca) durante mi etapa formativa. Las he ido descubriendo a lo largo de los años. (Entrevistada 2-2020).

Así pues, existiendo tantas músicas, parece ser que las mujeres que se dedican a esta profesión sienten la necesidad de conocerlas y darlas a conocer. Respecto a ello, varias entrevistadas mencionan que la responsabilidad de liderar el cambio recae sobre ellas, como miembros de una generación de 
mujeres que, aunque tienen hoy en día a los hombres como aliados en la lucha feminista, no pueden confiarles a ellos esta tarea, como tampoco se les niegan los beneficios que comporta para ambos sexos.

Considero que con nuestro trabajo somos partícipes y protagonistas de un cambio hacia una mayor visibilidad del papel de la mujer en diferentes campos profesionales y de un mayor calado social sobre la importancia y la relevancia del mismo. (Entrevistado 5-2019)

Considero que la situación actual aún es difícil, escasa e insuficiente. Pero también considero que nos abrimos paso con fuerza y que cada vez más proyectos, formaciones y producciones se suman a la normalización de esta realidad, en busca de un futuro en el que lo importante sea el proyecto, la acción cultural, independientemente de quien la integre. (Entrevistada 2-2017)

La entrevistada 2-2017 también muestra como un problema la falta de normalización de la profesión. En realidad, es un síntoma de este problema que se convierte en causa del mismo, pues se retroalimenta y, además, alimenta los prejuicios sociales con los que chocan quienes sí consiguen dedicarse a la dirección orquestal, tal y como confiesa la entrevistada 7-2019, y que tienen que ver con la diferente recepción de los estilos de liderazgo según el sexo del líder: si es un hombre, no se le suele cuestionar el hecho de tender a lo autoritario o a lo democrático, por ejemplo, mientras que si se trata de una mujer, cualquiera que sea el estilo que elija para desarrollar su trabajo, será medido por otro rasero:

A veces no es sencillo. En muchas ocasiones he escuchado comentarios que estaban fuera de lugar e incluso (cuando comencé a dirigir) de músicos que se han negado a trabajar conmigo. Con el tiempo, la situación ha ido cambiando. No obstante, todavía se hace extraño para muchos músicos que una mujer les dirija. Del mismo modo que al público, no está todavía acostumbrado a ver dirigir a una mujer. (Entrevistada 7-2019)

Respecto al trato recibido, y volviendo al fragmento de 7-2019 citado arriba, los eventuales comentarios machistas que sufren las mujeres, en este ámbito como en el resto, son reforzados por la recepción y actitud de los propios músicos que son dirigidos por una mujer y que la llevan, en no pocas ocasiones, a la necesidad de justificar de entrada su vocación o su osadía de invadir un terreno secularmente masculino tal y como se evidencia en la entrevista 5-2020: 
Para mí el mayor reto es que podamos dedicarnos a hablar de música, de procesos creativos, de expresividad y de técnica. Que no tengamos que justificarnos ni reivindicarnos todo el rato. Porque, si cerramos los ojos y escuchamos, difícilmente distinguimos si quien toca es hombre o mujer. Entonces, ¿ipor qué no hacer lo mismo con los ojos abiertos y avanzar todos juntos en esta búsqueda incesante que provoca el Arte? (Entrevistada 5-2020)

Por último, uno de los problemas que fisiológicamente afecta a las mujeres y no a los hombres es el embarazo. Ante las preguntas « $i$ Crees que las mujeres se encuentran en una situación distinta al sexo masculino? ¿En qué aspectos?», la entrevistada 14-2017 respondió afirmativamente precisamente en esta línea:

Sí, debido al proceso de reproducción. Son 10 meses más el resto del tiempo que las mujeres deben ocupar con los hijos y el marido. A pesar del mejoramiento las mujeres siempre hacen el doble de trabajo que los hombres [...]. La educación, el tiempo que la mujer debe dedicar a la familia, hijos, etc., la percepción de la imagen de la mujer en la sociedad [...]. Creo que la naturaleza ha puesto a la mujer en una situación difícil para competir con el hombre debido a que son ellas las que tienen bebés. No sé cómo se puede arreglar esto (entrevistada 14-2017).

No obstante, y aunque se menciona, por ejemplo, en el fragmento transcrito, no es ese el obstáculo principal relacionado con la maternidad que las directoras han encontrado en sus carreras, sino más bien el derivado de la crianza, algo sobre lo que vienen profundizando otros estudios desde hace unas décadas, como el de Bartleet (2006). Si tenemos en cuenta que esta es una tarea en la que los hombres también tienen responsabilidad, el hecho de que sean ellas quienes sienten el peso de la obligación familiar y la dificultad de conciliar con las exigencias profesionales no deja de ser un reflejo del sexismo impregnado en la sociedad. Así se percibe en los fragmentos seleccionados de las entrevistas 11-2016 y 19-2017.

La diferencia más grande que puedo ver es que muchas mujeres, como en mi caso, madres, nos vemos un poco postergadas en algunos momentos, y esto no tiene que ver con la diferencia, sino con la conciliación. Considero necesarias todas las medidas que lleven a mejorar la conciliación. (Entrevistada 11-2017)

Soy madre de dos niños pequeños y esposa de un hombre que trabaja mucho. Trato de equilibrar y no siempre es fácil. Mi día puede comenzar poniendo la lavadora, alguna comida en el horno y notas en el pentagrama. Ayudo a mi hijo 
con sus tareas, peino a mi hija y respondo mensajes... Es hacer todo al mismo tiempo. Mi mayor tiempo de concentración es por la noche, cuando todos duermen, entonces relego muchas veces horas de descanso, salidas sociales, etc., en función de estudiar o trabajar. Pero no me arrepiento. Lo disfruto plenamente. (Entrevistada 19-2017)

\section{DISCUSIÓN Y CONCLUSIONES}

Los resultados expuestos confirman lo hallado en investigaciones previas de las que se partió (Ravet, 2000, 2015; Soler, 2019) en cuanto a la gran brecha de género en el mundo profesional de la música culta. Según Soler (2019), las intérpretes deben hacer frente a una serie de dificultades (tales como la dificultad de compaginar este oficio con la familia; la escasa presencia femenina tanto en libros de historia de la música como encima del escenario en las orquestas más prestigiosas; la necesidad de demostrar constantemente qué son capaces de hacer, etc.), las cuales coinciden con las que encuentran las mujeres que dirigen la orquesta. Es decir, se documenta la pervivencia de las cuestiones señaladas por Soler (2019). Sin embargo, aquellas no tienen los problemas de liderazgo que sí se les presentan a estas, y que las enfrentan a concepciones patriarcales que la sociedad tiene asumidas de una manera inconsciente, y que en nuestro caso hemos visto que se manifiestan en desacreditaciones hacia la autoridad femenina.

Según Ravet (2000), los propios músicos de una plantilla orquestal no reaccionan del mismo modo ni en los ensayos ni durante el concierto en directo cuando la persona encargada de dirigirles es un hombre o una mujer. Así, la autora observó que cuando era una mujer quien dirigía, a menudo debía soportar ciertas actitudes negativas de los músicos hacia ella e incluso comentarios fuera de lugar simplemente por el hecho de ser mujer.

Lo que aportamos ahora es algo que quedaba por explorar en los estudios citados: la percepción sobre la dirección de orquesta desde un punto de vista femenino y sobre los obstáculos que en este ámbito se les presenta de manera específica a las mujeres, que siguen siendo pocas en el siglo XXI, como mostraba el informe ¿Dónde están las mujeres en la música sinfónica?, realizado por la asociación Clásicas y Modernas (Gutiérrez et al., 2019).

En conclusión, la presente investigación nos ha conducido a identificar los obstáculos principales que hacen que la presencia femenina en el ámbito 
de la dirección orquestal sea tan escasa. Estos pueden resumirse en siete ideas:

1. Fácil acceso a los estudios musicales para las mujeres, pero dificultades para desarrollarse posteriormente en el mundo laboral.

2. Falta de referentes femeninos que disminuyen la motivación.

3. Falta de normalización de la profesión de dirección de orquesta.

4. Problemas sociales en la recepción y actitud de los músicos que son dirigidos por una mujer.

5. Dificultades para conciliar la vida profesional y familiar.

6. Necesidad de justificarse a priori.

7. Iniciativas que propicien el cambio lideradas por las propias mujeres. Con todo, podemos constatar avances hacia la igualdad en esta profesión. En el campo de la dirección orquestal lo vinculamos con algunas de las iniciativas expuestas en el marco teórico, las cuales se documentan especialmente en los últimos años: presencia en la prensa, creación de nuevos premios exclusivamente para mujeres directoras de orquesta, congresos con perspectiva de género sobre la profesión, etc.

\section{REFERENCIAS BIBLIOGRÁFICAS}

AFP (2020a, 21 septiembre). Directoras de orquesta, una visibilidad «in crescendo». La Prensa. https://www.prensa.com/impresa/vivir/ directoras-de-orquesta-una-visibilidad-in-crescendo/

AFP (2020b, 17 octubre). Culmina certamen que busca dar visibilidad a directoras de orquesta. La Jornada. https://www.jornada.com.mx/ultimas/cultura/2020/09/22/culmina-certamen-que-busca-dar-visibilidad-a-directoras-de-orquesta-5271.html

Alger, B. E. (2018). Their Own Agenda: The History, Development and Culture of Women's Orchestras outside the United States. University of Maryland.

Bartleet, B. L. (2006). Conducting Motherhood: The Personal and Professional Experiences of Women Orchestral Conductors. Outskirts: feminisms along the edge, 15. https://www.academia.edu/18173950/ 
Conducting_motherhood_The_personal_and_professional_experiences_ of_women_orchestral_conductors.

Boisnard, G., \& Melander, J. (2018). Exploring Leadership Styles in the Music Industry [Tesina, Jönköping University]. http://www.diva-portal.org/smash/ get/diva2:1214738/FULLTEXT01.pdf

Calderón, D., Oriola S., \& Gustems, J. (2015). Liderazgo y música: la figura del director. Educación y Pedagogía, 10, 16-27. https:/www.e-revistes.uji.es/ index.php/artseduca/article/view/2008

Castillo-Mayén, R., \& Montes-Berges, B. (2014). Análisis de los estereotipos de género actuales. Anales de psicología, 30(3), 1044-1060. https://doi. org/10.6018/analesps.30.3.138981

De Laleu, A. (2016, 31 marzo). Femmes chefs d'orchestre: une évolution à petits pas. France Musique. https://www.francemusique.fr/actualite-musicale/ femmes-chefs-d-orchestre-une-evolution-petits-pas-685

ENS (2020, 25 septiembre). Directoras de orquesta, una lucha por tener la batuta. El Nuevo Siglo. https://www.elnuevosiglo.com.co/ articulos/09-25-2020-directoras-de-orquesta-una-lucha-por-tener-la-batuta

Franco, S. (2020, 18 septiembre). UAEH, presente en simposio de mujeres directoras de orquesta. El Independiente de Hidalgo.

Goleman, D. (2000). Leadership That Gets Results. Harvard Business Review, 78(2), 78-79.

Gould, E. S. (2003). Cultural Contexts of exclusion: Women College Band Director. Research \& Issues in Music Education, 1(1), 1-13. http://files.eric. ed.gov/fulltext/EJ852401.pdf

Gutiérrez, R., Pastor, P., Borja, M., \& Sánchez, S. (dirs.) (2019). ¿Dónde están las mujeres en la música sinfónica? Clásicas y Modernas. https://s3.amazonaws. com/fundacion-sgae/2019/Musica/donde_estan_las_mujeres_sinfonicas_ estudio.pdf

Lazarou, L. (2017). Women Conductors: A Qualitative Study of Gender, Family, «the Body» and Discrimination [Tesis doctoral, Durham University]. http:// etheses.dur.ac.uk/11965/

Leonardo (2020, 22 septiembre). Increíble. Directora de orquesta venezolana fue galardonada en el concurso de la Filarmónica de París. Gossip Venezuela. https://gossipvzla.com/increible-directora-de-orquesta-venezolana-fue-galardonada-en-el-concurso-de-la-filarmonica-de-paris/ 
LePage, J. W. (1980). Women Composers, Conductors, and Musicians of the Twentieth Century. Scarecrow Press.

López-Navajas, A. (2015). Las mujeres que nos faltan. Análisis de la ausencia de las mujeres en los manuales escolares [Tesis doctoral, Universitat de València]. https://roderic.uv.es/handle/10550/50940

McClary, S. (1991). Feminine Endings. University of Minnesota Press.

Noriega, M. (2010). The Montreal Women's Symphony Orchestra and the Emergence of Women as Orchestral Musicians in Canada (1940-1965) [Tesis doctoral, University of Calgary]. https://prism.ucalgary.ca/handle/1880/104548

Oppegard, K., David, S., Elkins, E., Abbenante, J., \& Bangley, B. B. (2005). Choosing Art Therapy as a career. Art Therapy: Journal of the American Art Therapy Association, 22(2), 92-100. https://doi.org/10.1080/07421656.2005. 10129444

Ortega, F. (1998). Imágenes y representaciones de género. Asparkía, 9, 9-20. http://www.e-revistes.uji.es/index.php/asparkia/article/view/940/849

Park, G., Yaden, D. B., Schwartz, A. H., Kern, M. L., Eichstaedt, J. C., Kosinski, M., Stillwell, D., Ungar, L. H., \& Seligman, M. E. P (2016). Women are Warmer but no Less Assertive than Men: Gender and Language in Facebook. PLoS ONE, 11(5), 1-26. https://doi.org/10.1371/journal.pone.0155885

Pendle, K. (1991). Women \& Music: A History. Indiana University Press.

Piña, M. C. (2020, 23 septiembre). «La Maestra», el primer concurso para directoras de orquesta se hizo en París. RFI. https://www.rfi.fr/es/cultura/20200923-la-maestra-el-primer-concurso-para-directoras-de-orquesta-se-hizo-en-par\%C3\%ADs

Ravet, H. (2000). Les musiciennes d'orchestre: interactions entre représentations sociales et itinéraires. Université Paris Ouest-Nanterre la Défense.

Ravet, H. (2015). L'Orchestre au travail. Interprétations, négociations, coopérations. Vrin-MusicologieS.

Rhodes, J. (2014, 4 febrero). Sexism is Rife in Classical Music. The Guardian. https://www.theguardian.com/music/2014/feb/04/ sexism-rife-classical-music-marin-alsop-james-rhodes.

Ridgeway, C. L. (2008). Framed Before We Know it: How gender Shapes Social Relations. Gender \& Society, 23(2), 145-160. https://doi.org/ 10.1177/0891243208330313

Sau, V. (2000). Diccionario ideológico feminista. Icaria (3. a ed.). 
Scharff, C. (2018). Gender, subjectivity and cultural work: the classical music profession. Routledge. https://doi.org/10.4324/9781315673080

Soler, S. (2019). Mujeres músicas. Dificultades, avances y metas a alcanzar en el siglo XXI. Universitat Jaume I. https://doi.org/10.6035/Sendes.2019.24

Valls, L. (s/f). TOP 10: Mujeres directoras de orquesta. Mujeres y Música. https:// mujeresymusica.com/mejores-mujeres-directoras-de-orquesta/ 